\title{
Developing an Intelligent Automation and Reporting System for Fabric Inspection Machines
}

\author{
Cihat Okan Arıkan* \\ Ege University, Department of Textile Engineering, 35100, Bornova, İzmir, Turkey
}

Corresponding Author: Cihat Okan ARIKAN, cihat.arikan@ege.edu.tr

\begin{abstract}
In textile companies, the detection of defects and unacceptable areas of fabrics at the quality control stage has great importance for apparel production, although it is also a post-manufacturing operation for weaving and knitting mills, today it is still mostly being carried out on the guidance of human perception and sensory abilities. Such quality control operations are based on the attendant employee's detection of the defects and the unacceptable areas by visual inspection and scanning the overall fabric structure which is being transported on a brightly illuminated straight plane. The detected defects during the scanning operation are recorded on the defect charts and these outcomes subsequently are subjected to the quality control supervisor's evaluation and thereafter, it is decided whether the related inspection reports would exemplify an appropriate fabric to be used in production or not. In this study, it is aimed to develop a new system which enables to integrate the empirical paperwork-based reports that are still being commonly utilized by the majority of the textile companies in to the contemporary technology and also allows to compare such reports with the previous ones when it is necessary. The proposed system development consists of a fabric inspection machine which is equipped with a PLC-controlled digital display or in other words an intelligent control, and a web based software that enables the controller to analyze the reports comprehensively and simultaneously those of produced by this system, The system, which renders paperwork reports obsolete, allows the reports to be viewed on computer screens as soon as the inspection was completed. This feature ensures that all of the fabric rolls within the same order, multiple batches or bundles to be displayed on a single screen. Thus, it permits to determine the usability of the fabric for the production via employing the four-points system which is one of the prevailing methods for quality control procedures in the industry. Consequently, it is aimed to achieve significant time and labor savings in textile companies via utilizing this new developed system.
\end{abstract}

\author{
ARTICLE HISTORY \\ Received: 04.12.2018 \\ Accepted: 06.03.2019
}

\section{KEYWORDS}

Fabric Inspection, Intelligent Automation Systems, Defect Reporting

\section{INTRODUCTION}

The fabric defects may cause $45-65 \%$ incurred loss in sale prices. Besides, approximately $85 \%$ of the product rejects in the apparel industry are related with fabric defects. The woven cloth width is mostly in $1-3 \mathrm{~m}$ range. The quality control employees perform the task of quality inspection over a fabric which is moving on an illuminated board with a velocity of $8-20 \mathrm{~m} / \mathrm{min}$ and even under the optimum conditions, they can perceive only $60 \%$ of the defects. Likewise, the amount of concentration time of a quality control employee is limited to 20-30 minutes, nonoccurrence of any defect in consecutive 20 seconds deteriorates the attention span and these adversities induces a limitation of only conspicuous defects to be recognized. It is surveyed that nearly $30 \%$ of the defects were elusive even under the test conditions and yet in the companies considered as good operating ones, the repeatability of defect evaluations failed to go beyond $50 \%$ among the quality control staff [3, $4,6,7]$. Therefore, the automation of weaving monitoring is an extensively researched topic [2].

To cite this article: Arlkan C.O., 2019, "Developing an Intelligent Automation and Reporting System for Fabric Inspection Machines" Tekstil ve Konfeksiyon, 29 (1), pp:86-93. 
It is quite possible to encounter disparate fabric defects on the woven fabrics during quality control stages, which would be used for garments, underwear, home textiles and various textile items. There might be various defects on the fabrics such as punctures, holes, stop marks, broken -deformedtorn selvedges, dying-color-tone differences, soiling and oil marks, crease marks, pattern imperfections, weft skewness, color matting, strength losses, hardening, rapier and reed marks, broken, thin, thick warp or weft yarns, uneven yarns, barré effects, loose yarns, missing yarns, foreign matters, knots, fuzzy surfaces, nodes, impurities, and wrinkles etc. [5].

The fabric quality control departments of the mills usually inspect the fabrics either by laying down the fabric on a flat surface or moving the fabric by means of a fabric inspection machine. When the quality control employee detects a defect, records this instance on a form which is similar to the example given in the Figure 1. Later on, these forms will be submitted to the quality control supervisor in order to be evaluated for deciding the related fabric's appropriateness for production.

In the evaluation stage, the Four-Points System, a standard established under ASTM D5430-07 (2011), is used as the Four-Points System is widely accepted and worldwide recognized in fabric inspection due to its practical, impartial and unbiased methodology. The Four-Points System assigns 1, 2, 3 and 4 penalty points according to the size, quality, and significance of the defects. No more than 4 penalty points is assigned for any single defect. A defect can be measured either length or width direction; the system remains the same. Only major errors are taken in to account. No penalty points are assigned to minor defects. Whenever errors are recognized during fabric inspection under four-points system and all defects must be assigned a number of points depending on the severity or length [8]. Many mills grade fabrics as first quality and second quality instead of just Pass/Fail the fabric roll or fabric lot. Grading is done based number of penalty points per 100 square yards. The acceptable points can be defined as points per 100 linear yards as well as points per 100 square yards. In general, acceptable level of 'points per 100 linear yards' or 'points per 100 square yards' are different for different fabric types. For example: For cotton twill/denim 28 points per 100 square yards (23 points per 100 square meters) for individual fabric roll, likewise, for all synthetic fabrics 20 point per 100 square yards (16 points per 100 square meters) for individual fabric roll are assigned as minimum acceptable points.

\section{MATERIAL and METHOD}

\section{Fabric Inspection Machine Equipment}

In this study, the data were collected from KMS Inspection Machines (KKONMTF) which were installed at AEM Textile Company and GMC Textile Company. These machines are produced for quality inspection of fabric rolls and consist of the illuminated fabric inspection board, fabric take up roller and the right-hand side located PLC controlled intelligent display featuring a touch panel as shown in Figure 1. The technical specifications of the machine are given in Table 1.

Table 1 Technical specifications of the fabric inspection machine

\begin{tabular}{|l|l|}
\hline TECHNICAL SPECIFICATION & DEFINITION \\
\hline Maximum Fabric Width & $160 \mathrm{~cm} \ldots 350 \mathrm{~cm}$ \\
\hline Maximum Fabric Roll Diameter & $40 \mathrm{~cm}$ \\
\hline Maximum Fabric Weight & $150 \mathrm{~kg}$ \\
\hline Maximum Speed & $60 \mathrm{~m} / \mathrm{min}$ \\
\hline Machine Width & $175 \mathrm{~cm}$ \\
\hline Machine Length & Fabric Width $+90 \mathrm{~cm}$ \\
\hline Machine Height & $190 \mathrm{~cm}$ \\
\hline Machine Weight & $530 \mathrm{~kg} \ldots 650 \mathrm{~kg}$ \\
\hline Electricity & $220 \mathrm{VAC}, 50 \mathrm{~Hz}$ \\
\hline
\end{tabular}

The utilized fabric machine is designed upon the basis of loading fabric roll from front side, and transporting fabric over the illuminated board to the back side and finally rewinding fabric at the bottom side of the machine as roll. The length and the current location of the fabric is being registered by the PLC-controlled stepper motor which is installed at the right-hand side of the illuminated board. The data from PLC can simultaneously be viewed on the righthand side mounted intelligent display (Figure 2).

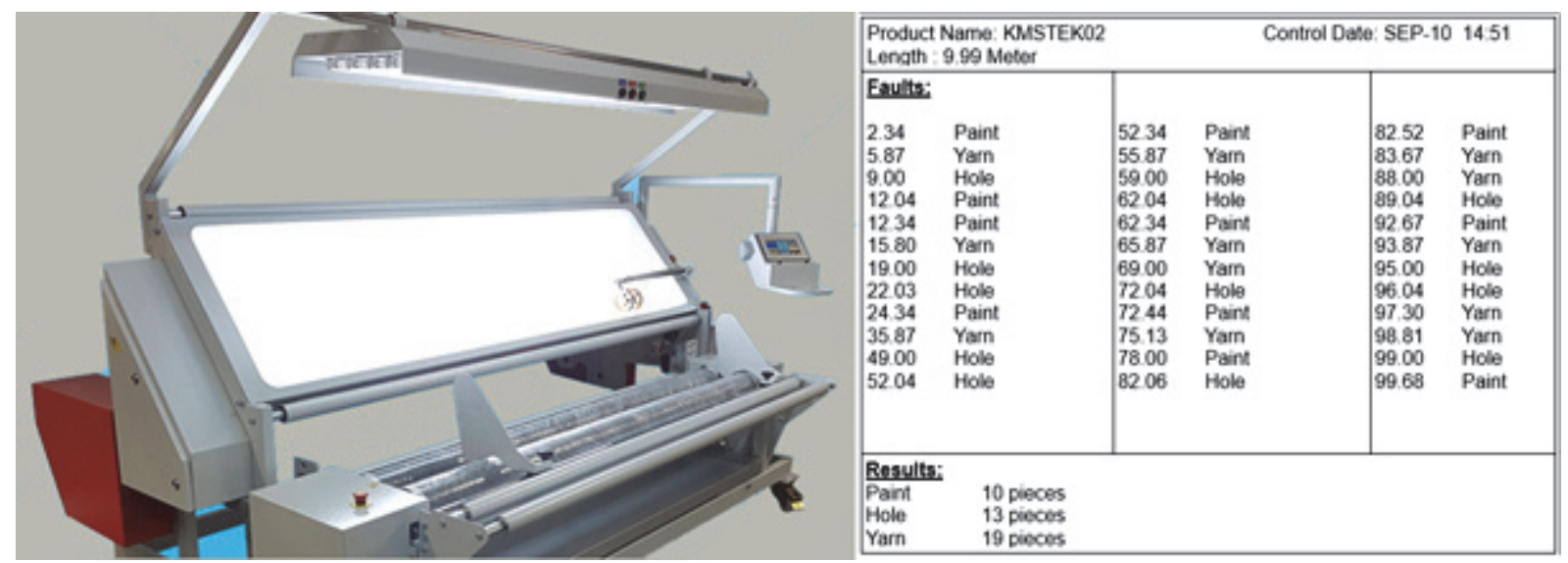

Figure 1. A fabric inspection machine equipped with a fabric inspection unit (LH), and an example of recorded list (RH) 


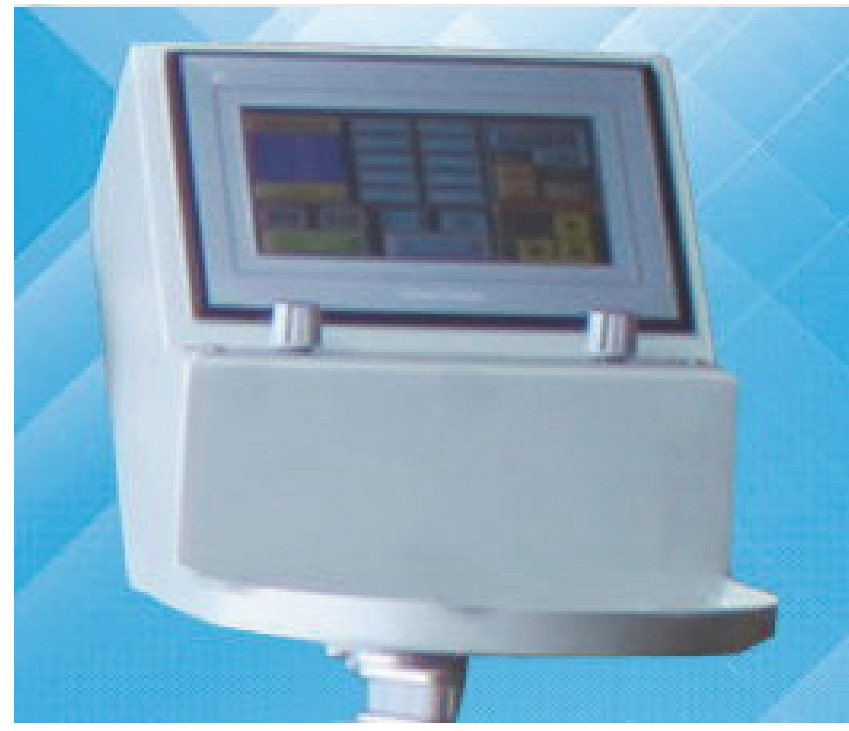

Figure 2. PLC-controlled intelligent display of fabric inspection machine

The inspector can carry on the resetting and fabric roll definition operations after placing the fabric over the illuminated fabric board. The resetting operation, by assigning the step motor distance of PLC to 0 , enables to measure the fabric correctly beginning from the 0 point.
Following the resetting operation, the order, batch and the other definitive information of the fabric to be measured fabric are entered in the related fields on the display (Figure $3)$.

The defect titles on the middle of the screen is defined in the screen settings by the inspector before starting the operation. Thus, it is possible to assign the defect softkeys variably according to the specific requirements. It is also allowed to add suffixes (-BEG) and (-END) to the defect titles for continuous defects of certain lengths (e.g. HOLE$B E G$ or HOLE-END). After entering the definition inputs, the machine is operated via pressing the "Start" softkey on the main screen and then the fabric begins to flow over the illuminated board. Along with the commencement, the inspector is supposed to press the related defect softkey on the machine display upon noticing any defect thus enabling the encountered defect to be recorded together with its longitudinal coordinates in the registry list (according to the type of the defect, the length of the defect also can be entered via screen and recorded in the list). This operation is maintained along with the whole fabric length and upon completing the inspection of the fabric roll, all of the collected data is stored in the memory of the machine in "CSV" (comma delimited file) file format by pressing the "SAVE" softkey on the screen (

Figure 4).

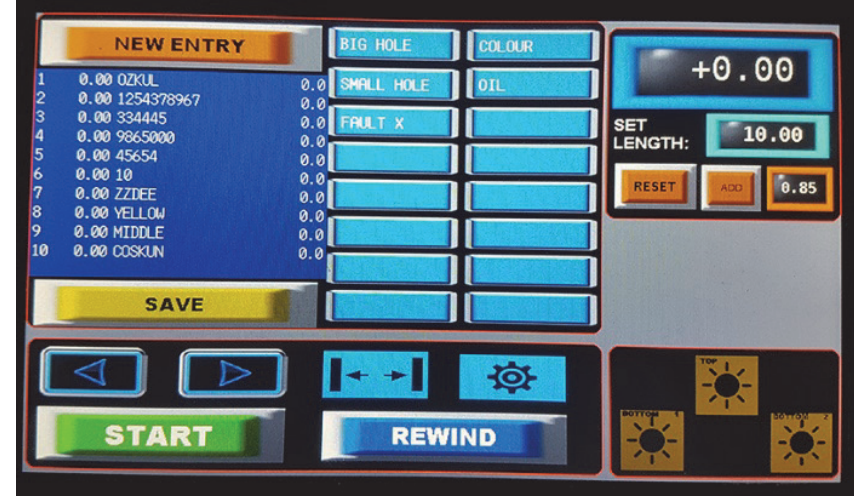

MATERIAL INFORMATION

Supplier:

Delivery Note No.

PO No.:

Batch/Lot No.:

Roll/Bale No.:

Quantity:

Description:

Colour:

ID/Quality:

Operator:

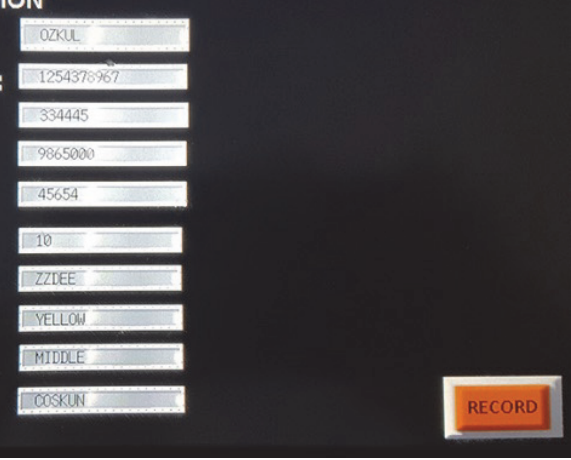

Figure 3. Fabric inspection machine, intelligent display, and product description page.

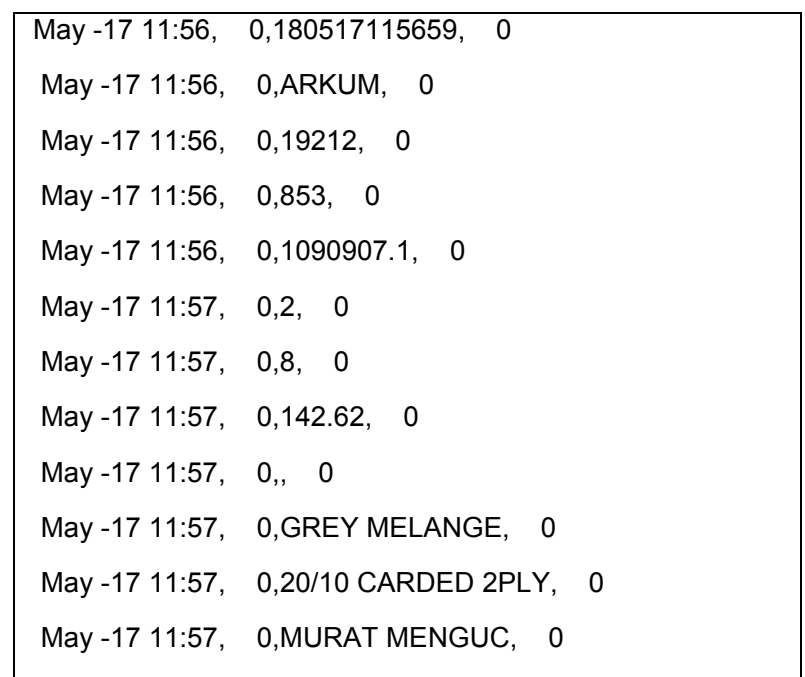

\begin{tabular}{|l|} 
May -17 12:00, 997,SANS SLIP, 0 \\
May -17 12:00, 997,JUT, 10 \\
May -17 12:02, 1749,SPOT, 10 \\
May -17 12:08, 2362,SPOT, 300 \\
May -17 12:09, 2484,SPOT, 10 \\
May -17 12:09, 2525,SPOT, 10 \\
May -17 12:12, 2960,SPOT, 400 \\
May -17 12:14, 2986, HOLE, 250 \\
May -17 12:16, 3475,SPOT, 20 \\
May -17 12:18, 3734,ROLL LENGTH, 0
\end{tabular}


Figure 4. CSV file of the fabric inspection machine processed fabric roll

The created CSV files will be saved on a USB memory device which is plugged in the USB port of the intelligent display. These files can be transferred either via an USB memory device or a FTP connection.

\section{The Developed CSV Analysis and Reporting Software (Delphi Version)}

The software that designed in this study was developed in two-stages. At first, it was compiled with Delphi programming language without having any database connection and capable of only analyzing the created singular CSV files with bilingual localization support for Turkish and English. Thereafter, in accordance with the requirements of the companies, the necessity of simultaneous analysis of order related fabric batches and batch related fabric rolls was evidenced. Therefore, the software was improved to be integrated with a database and the data that obtained from CSV files to be transferred to this database for being able to achieve multiple evaluation and comparison features. For this purpose, the necessary tables were created and integrated in to the MySQL server at the second stage of development. The first versions of the software were running with Ubuntu 14 server on a Raspberry PI based mini PC. The quality control supervisor, runs the software that was developed in this study on PC which was installed in supervision room and via network connection, automatically imports the measurement outcomes stored in the machine. Then, the imported CSV files are automatically analyzed and converted to the individual reports by the developed software. The analysis outputs that belong to the

Figure 4 represented CSV file are shown in Figure 5.

Following the deployment of the software, numerous updates were introduced in accordance with the requests of the companies. It was enabled to generate much more versatile outcome reports by incorporating the advantages of utilizing a database (Figure 6).

\section{The Developed CSV Analysis and Reporting Software (Web Version)}

Along with the increased deployment and continuous improvements, it was frequently encountered with difficulties related to the updating via intranet network of the companies. For being able to overcome such difficulties, it was concluded that a web based and less resource demanding version would be more applicable. At the beginning, the web server was operated by using Raspberry PI accommodated Apache. But it was encountered Raspberry $\mathrm{PI}$ access and maintenance related issues at most of the companies. Thus, the system was modified for allowing to be operated directly on the computers of quality control staff. By this way, the operation was continued by installing the required database and web server software on any intranet connected single computer in portable manner. The web version was developed in Bootstrap capable, by using PHP and Angular.JS. By this means, an infrastructure that allows to be operated on any type of device (PC, tablet, smart phone etc.) and to access the outcome reports any time was established (Figure 7).

All of the fundamental features of Delphi software is integrated in to the web interface of CSV analysis and reporting software. Automatic importing of CSV files from fabric inspection machine and processing them as well, classification of the defects, machine, simultaneous displaying of batch related rolls and order related batches along with the capability of correcting all of the missing or erroneous information, ability of recognizing any fabric roll with erroneous or missing information for grouping them under a general header and then allocating them to the correct order/batch stacks, point assignment for the defects in compliance with the four points method, and various similar features are made available in this version.

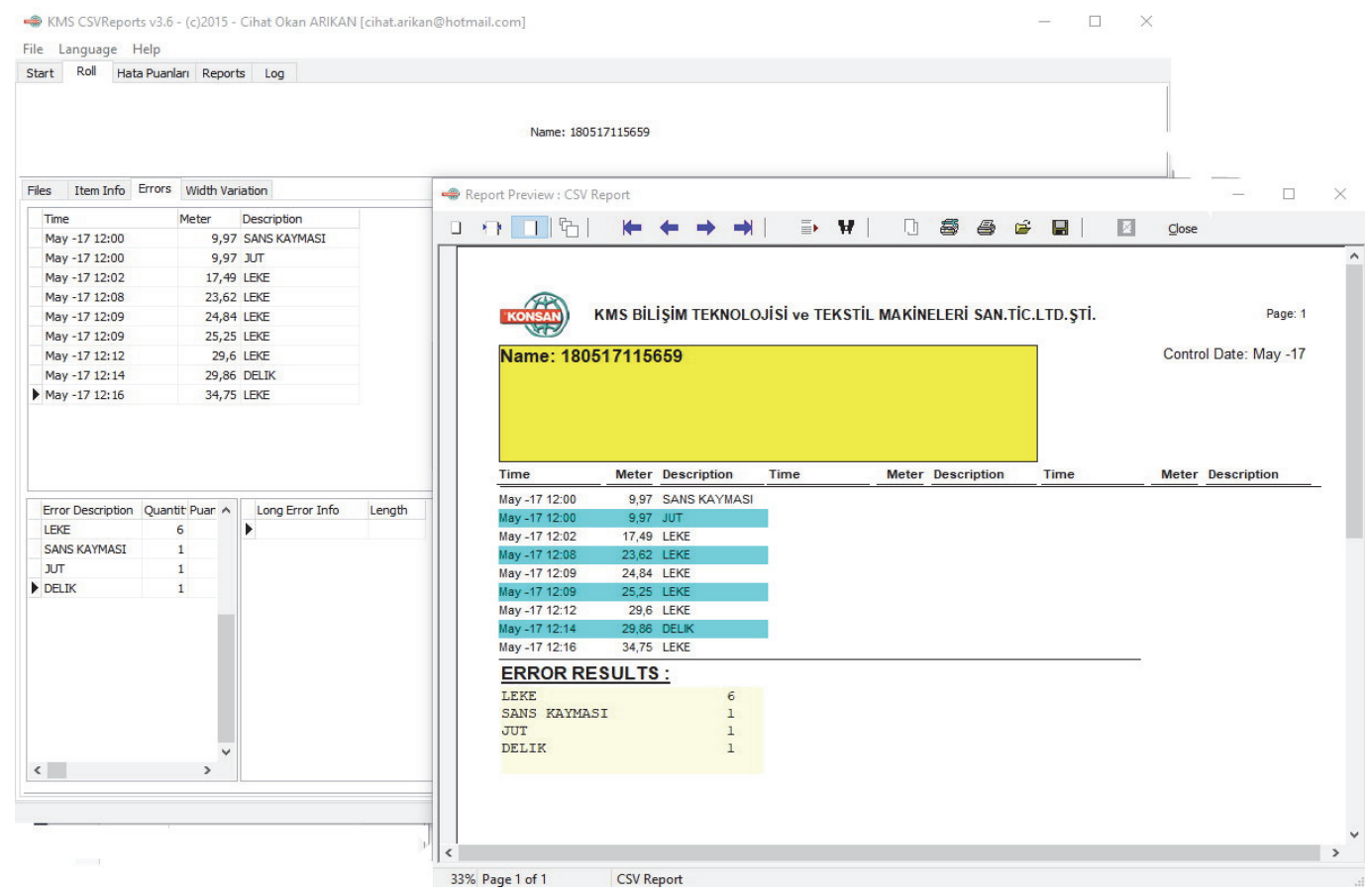

Figure 5. Report screen-shot of the first version of CSV analysis software 


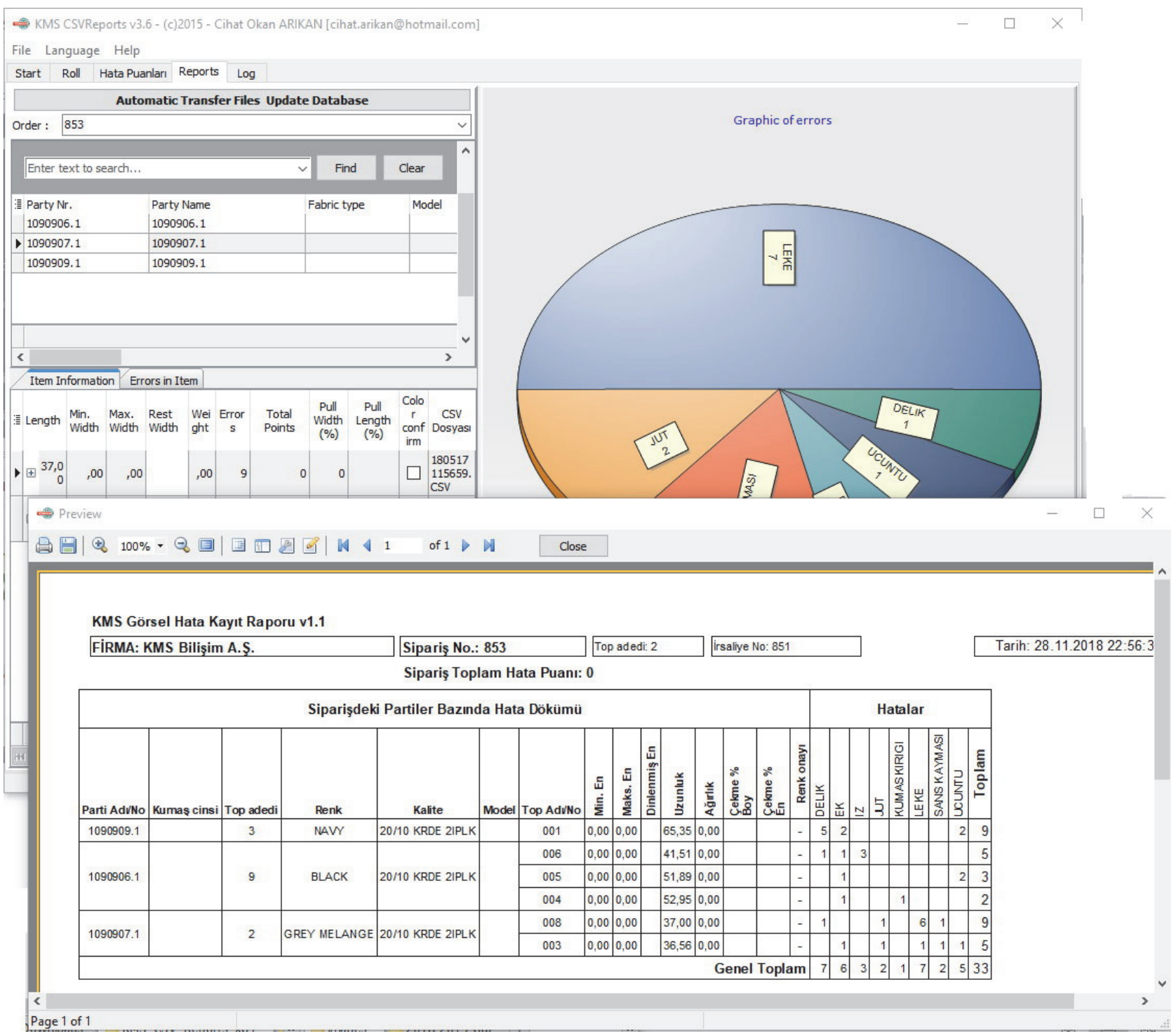

Figure 6. Detailed report output screen-shot of the new version of CSV analysis software

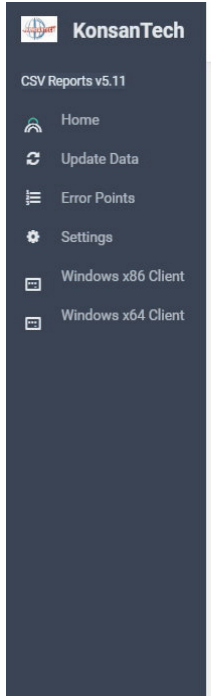

\begin{tabular}{|c|c|c|c|c|c|c|}
\hline \multicolumn{7}{|c|}{$\begin{array}{l}\text { Ordering Information } \\
\text { Orders of fegistered paty-ball-eror numbers and score }\end{array}$} \\
\hline Order number & Number of parties & Number of balls & Total Error & Total Points & & $\begin{array}{l}\text { Edit/ } \\
\text { Delete }\end{array}$ \\
\hline 976 & & 111 & tith & 35 & 61 & (ब) Dell \\
\hline \begin{tabular}{|l|l|}
1090907.1 \\
\end{tabular} & 2 no & nd & 50 & 50 & 91 & 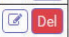 \\
\hline 853 & & 3 & 6 & 3 & 59 & (8) Del \\
\hline 38 & one & ne & 8 & 32 & 71 & (ब) Del \\
\hline 37 & one & ne & 3 & 66 & 128 & (ब) Del \\
\hline 36 & $2 \mathrm{nd}$ & nd & 79 & 79 & 130 & (8) Del \\
\hline 664 & $2 \mathrm{nd}$ & nd & 26 & 26 & 80 & (8) Del \\
\hline 4567.8 .1 & one & on & ne & 4 & 13 & (8) Det \\
\hline 851 & & 4 & 222 & 22 & 742 & (8) Det \\
\hline Add New Order & & & & & & \\
\hline
\end{tabular}

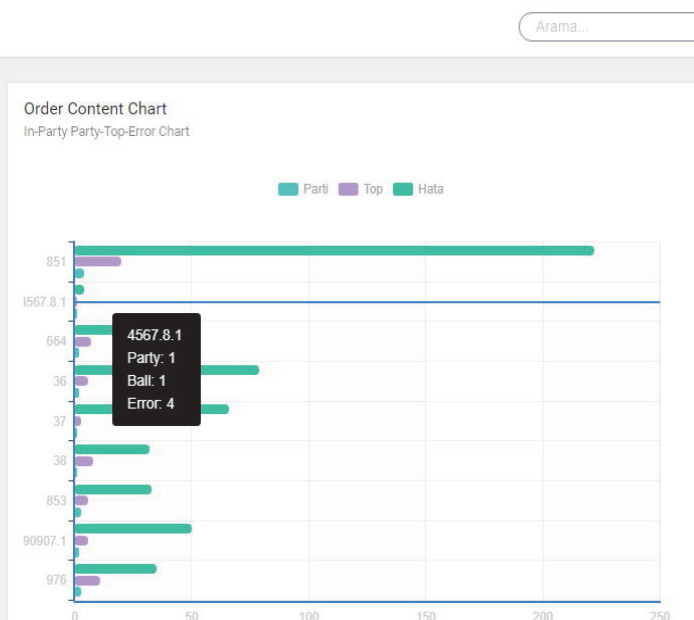

Figure 7. Main screen of CSV analysis and reporting software web version 


\section{Analysis and Reporting}

The developed software in the context of this study (both PC based and Web based versions), aimed to offer automated solutions for classification of plain text files (CSV) created at the fabric machine along with rendering meaningful as well and thereby, service to the quality control supervisor during the evaluation process associated with fabric rolls, batches and finally entire order. It is configured for counting the same defect types, calculating their percentile share in the total problem account, assigning the point allocation of defects according to four-points system, and consequently assisting the quick decision making about the usability of fabric rolls in production. For this purpose, the CSV file which is given as an example in the

Figure 4, is converted in to a list as shown in the Figure 8 , by applying the web based version for analysis and calculations.

\section{RESULTS}

The test data of this study were collected at the quality control department of a contributing company having fabric inspection machines installed, from a sampling consisting of 1300 fabric rolls, between the dates of 22.11.2017 11.09.2018 The manual procedure is executed as follows, the inspector fills out a paper template form for each fabric roll processed, upon completion of a batch the outputs are submitted the quality control supervisor, henceforth, the outputs are transferred in to a MS Excel worksheet (Figure 9) and various calculations are made to achieve best available evaluations.

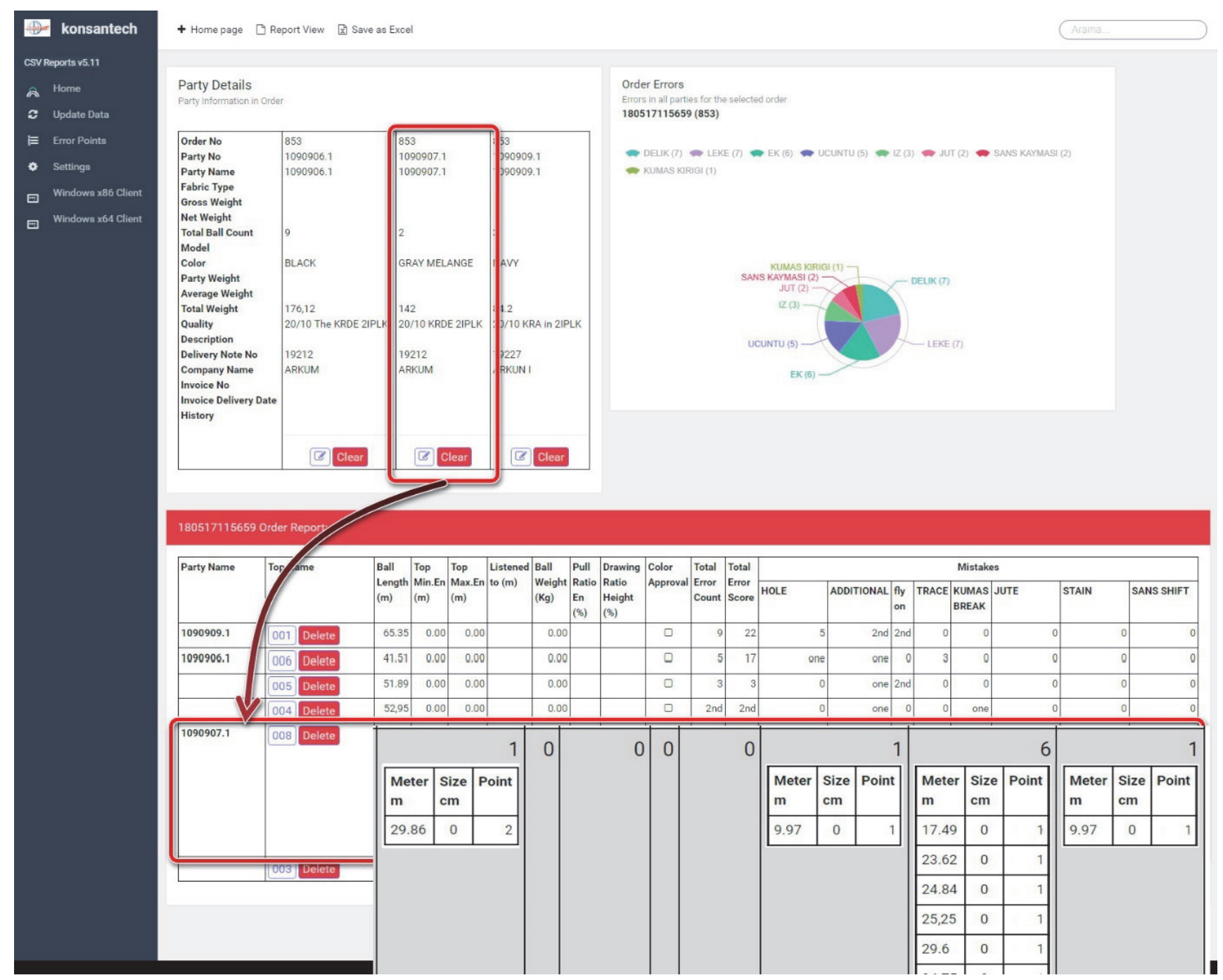

Figure 8. Screen output obtained via web version for analysis and reporting 


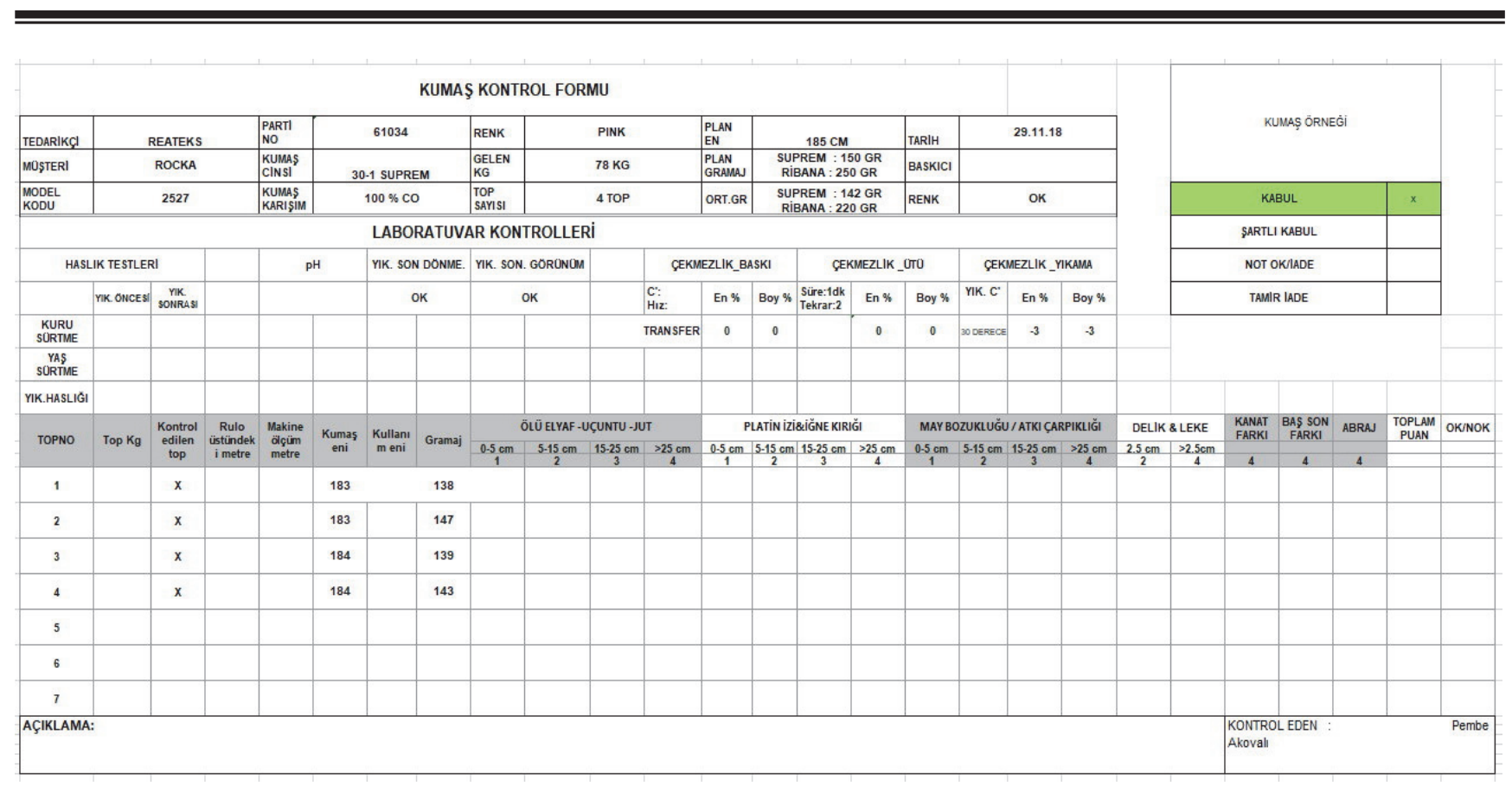

Figure 9. Manual process based Excel file constructed by quality control staff before the software usage

These operations induce enormous amount of time loss for quality control supervisor. The excessive number of start/stop instances is tiresome for the inspector and limits the inspector's productivity to $8-10$ rolls per shift. Moreover, quality control supervisor is ought to evaluate the MS Excel worksheet of outputs by herself/himself according to the four-points method which requires at least one day to complete. Because of this, the decision about the fabric is made without utilizing the four-points method, instead, on the basis of personal experiences and expertise. Any arisen problems in the bulk production because of such insufficiencies may lead to significant economic and time losses concurrently. Table 2 and Figure 10 reveals the comparative time saving benefits obtained from fabric analysis of an order (consisting of 4 batches) which was subjected once to manual procedure and once to software assisted procedure.

Table 2 Comparison table of manual method generated versus intelligent display + software generated analyses and reporting times

\begin{tabular}{|l|l|l|l|l|l|}
\hline Batch Nr. & $\begin{array}{c}\text { Number } \\
\text { of rolls } \\
\text { in the } \\
\text { batch }\end{array}$ & $\begin{array}{c}\text { Time (minute) required for manual } \\
\text { inspection of fabric rolls and } \\
\text { recording on paper }\end{array}$ & $\begin{array}{c}\text { Identified error counts } \\
\text { on the fabric }\end{array}$ & $\begin{array}{c}\text { Time (minute) for } \\
\text { converting paper data } \\
\text { into Excel worksheets }\end{array}$ & $\begin{array}{c}\text { Total } \\
\text { time } \\
\text { (minute) }\end{array}$ \\
\hline 1090906.1 & 9 & $15+18+12+20+19+17+20+19+22(162)$ & $4+3+3+2+5+0+3+3(23)$ & 18 & 180 \\
\hline 10668 & 2 & $13+18(31)$ & $5+2(7)$ & 5 & 36 \\
\hline 1090909.1 & 3 & $10+13+17(40)$ & $5+3+6(18)$ & 13 & 53 \\
\hline 118933 & 6 & $35+30+45+8+16+21(155)$ & $5+2+0+5+1+2(15)$ & 11 & 166 \\
\hline
\end{tabular}

\begin{tabular}{|l|l|l|l|}
\hline Batch Nr. & $\begin{array}{l}\text { Number of rolls } \\
\text { in the batch }\end{array}$ & $\begin{array}{l}\text { Time (minute) required for inspection and recording via } \\
\text { intelligent display and developed software }\end{array}$ & Saved time (minutes) \\
\hline 1090906.1 & 9 & $13+14+9+16+16+14+13+14+16(125)$ & 55 \\
\hline 10668 & 2 & $7+10(17)$ & 19 \\
\hline 1090909.1 & 3 & $7+8+10(25)$ & 28 \\
\hline 118933 & 6 & $22+21+31+5+11+15(105)$ & 61 \\
\hline
\end{tabular}




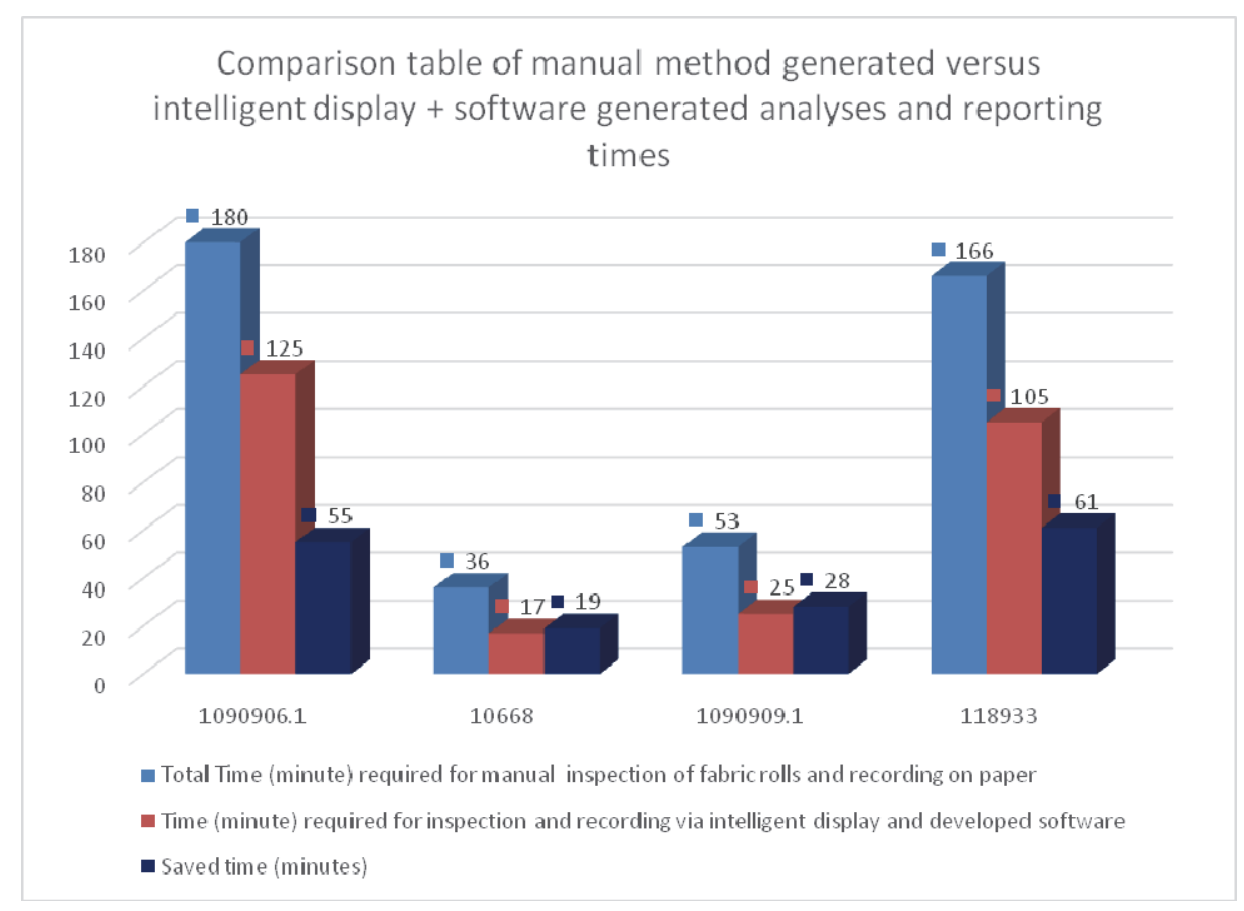

Figure 10. Comparison Graphic of manual method versus software generated analyses

The results in the Table 2 and Figure 10 represent only randomly selected samples from one week's work. For the manually performed measurement outcomes, the working time spent by the quality control supervisor for transferring data to MS Excel file (Figure 9) and working in MS Excel worksheet was not included with full of data (because of the company policies, related data was not permitted to use out of the company). Therefore, it is obvious that the inclusion of that excluded time would increase the difference even more.

\section{CONCLUSION}

In this study, it is aimed to develop a new system in order to ensure that the reports which are prepared on paper in many companies can be rearranged in accordance with today's technologies and compared with previous reports when necessary. The developed system, which is called as "smart control", is consists of a PLC controlled digital display equipped with a fabric control machine and the reports produced from here, in which the controller will be able to examine the instant and detailed web-based software. The system, which eliminates all operations on paper, allows the reports to be viewed instantly from the computer screens as soon as the control ends.
In this study, a total of 1300 fabric rolls were analyzed in the Quality Control Department of a textile company using fabric control machine and developed software.

According to the results, it can be concluded that, employing the software that developed in this study yielded, either in Windows OS or in platform independent web-based version, much more rapid results than manual method. It is assessed that this software which was developed in the context of this study would aid to achieve significant time savings in garment manufacturing companies. The development of the software is still on progress and is mostly based on the feedback from contributing companies. It is planned the improve the software even more by adding the following features such as automatic report output at predetermined time intervals and also to be sent simultaneously to the quality control supervisor, generation of roll, batch, order based accept/reject results in accordance with the defects rates by full-fledged integration of four-points method. There is also an ongoing improvement thread accompanying this software development, aiming to operate this system via a simple computer instead of an intelligent display for being able to reduce the investment costs in today's intensively competitive market conditions.

\section{REFERENCES}

. Bek G.A., Sabır E.C., "Bir Konfeksiyon Fabrikasında Proses Ve Kalite Kontrol”, Ç.Ü Fen Bilimleri Enstitüsü Yüksek Lisans tezi, 2008, Cilt:19-1

2. Büyükkabasakal, Kemal, "Kumaş dokuma hatalarının tespiti ve sınıflandırılması", İzmir, Ege Üniversitesi, 2010

3. Cho, C-S., Chung, B-M., Park, M-J., 2005, “Development of Real-Time Vision-Based Fabric Inspection System”, IEEE Trans. on Ind. Elec., Vol. 52, No. 4,pp. 1073-1079, Aug 2005

4. Kısaoğlu, Ö., 2002, "Orta Büyüklükte Bir Dokuma İşletmesinde İstatistiksel Kalite Kontrol Sisteminin Kurulması”, Yüksek Lisans Tezi, Dokuz Eylül Ü.,Fen Bil. Ens., 2002

5. MEGEP, "Mesleki Eğitim Ve Öğretim Sisteminin Güçlendirilmesi Projesi”, Giyim Üretim Teknolojisi, Kumaş Kontrolü, Ankara, 2007

6. Meier, R., 2001, “Uster Fabricscan Akılı Kumaş Kontrolörü”, XI. Uluslararası İzmir Tekstil ve Hazır Giyim Sempozyumu, İzmir, Ekim 2001

7. Meier, R., Uhlmann, J. and Leuenberger, R., 1999, “Automatic quality inspection for the weaving mill”, International Textile Bulletin, No. 3, pp.46-49, 1999

8. Omar, F., Tekstile Study Center, "Fabric Inspection | Four-Points System”, Web blog: https://textilestudycenter.com/fabric-inspection/, April 2018 